\title{
A Study on Hedges of Spokesperson Remarks in Whitehouse Press Conference from the Perspective of Pragmatics
}

\author{
Zhenzhen Xiang \\ Guizhou Minzu University, Guiyang, China \\ sandy.xiang@qq.com
}

\begin{abstract}
Keywords: Hedges; Press conference language; Cooperative principle; Positive face strategy; Negative face strategy
\end{abstract}

\begin{abstract}
This paper describes and analyzes the hedges frequency and its pragmatic functions of Spokesperson remarks in Whitehouse press conference in perspective of Cooperative Principle and Face Theory. From the perspective of pragmatics, the qualitative and quantitative research methods are employed to analyze hedges in press conference language. The present research randomly selects five transcripts of spokesperson remarks in Whitehouse press conference to make a corpora as the research subject. On one hand, based on K. Hyland's definition and Prince et al.'s classification, hedges are identified and selected. On the other hand, hedges in the corpora are further analyzed from the point of Cooperative Principle and Face Theory. High frequency of hedges in spokesperson remarks is because positive and negative face strategy are frequently used by Whitehouse spokesperson in press conference, especially indirect devices, devices of minimizing the imposition and devices of hedges in negative face strategy.
\end{abstract}

\section{Introduction}

As an important property of natural language, hedges exist in all aspects of language. It plays an important role in human communication because of its flexibility and richness. Vagueness in language is once thought to be bad or defect. While Ullmann (1962) states that vagueness, as a matter of fact, is a kind of advantage ${ }^{[1]}$. Electrical Engineering expert Lofti Zadeh in the university of California put forward for the first time the term of fuzzy set, which was later applied in many areas, such as Math, linguistics, psychology, economics and so on. But it did not arouse people's interest until American Linguist George Lakoff first proposed hedgesin 1972. He made his study primarily at the semantic level. The words like sort of, or so, strictly speaking make the discourse even fuzzier.

\section{Definition and Classification of Hedges}

Based on Lakoff's definition, Prince, Bosk and Frager (1982) further classify hedges into two types, approximators and shields ${ }^{[2]}$. The approximators can be subdivided into two kinds, namely, adaptors, such as kind of, quite, kind of, etc. and rounders, such as roughly, about. The shields can be subcategorized into plausibility shields, such as I believe, I assume, I think, etc. and attribution shields, such as it is said that..., the scientists state that..., the statistical data show that..., etc. Kennedy (1987) conducted research on vague words based on corpus, which provided a new perspective of applied linguistics. He found that there is one vague word in every seven word. It is apparent that vague devices is quite normal in people's daily use ${ }^{[3]}$.

\section{Press Conference Language}

American Whitehouse news spokesperson system starts early and gets mature quickly worldwide. In 1950s, America set up news room and spokesperson in Whitehouse, which is followed by many countries in the world ${ }^{[4]}$. Political reform requires American government to make the information transparent to the public. Besides, American Presidents and spokespersons are usually good at public speaking. They know the necessity of using hedges in their language to deal with the sensitive events and 
safeguard national interest. Thus, it is necessary to explore the pragmatic functions and social communication functions of hedges.

The features of press conference language decides its importance. First, it has to be formal because spokesperson must represent the government to impart information to the mass media and help the government to have a good image to the public. Greeting is necessary at the beginning of the press conference and it is with questions raised by journalists. For example, American president Obama with Good afternoon as the starter and with the sentence let me first make a couple of quick points, and then I'll take your questions to proceed. At last, the press conference usually ends with a good wish or a polite acknowledgement. For instance, So I just want to close by wishing all of them a very Merry Christmas and a Happy New Year.

Second, press conference language should be frank ${ }^{[5]}$. Spokesperson speaks for the government and tells the public the latest news timely and exactly. Besides, they have to answer questions and deal with people's worries. Spokesperson better know the situations in the related areas and tell the truth. Otherwise, people would doubt about the government ability and even make the rumors everywhere. Therefore, spokesperson can choose not to answer the question. But they cannot avoid the question. If the questions are beyond their working area, they should also tell the journalists frankly. For example, $I$ think they would be the first to acknowledge that.......

Third, spokesperson has to use hedges in their languages in order not to make the press conference embarrassed ${ }^{[6]}$. No matter what situation it is, spokesperson cannot be irritated by the journalists. They can only use various language skills to make a good press conference. Sometimes they use hedges to give vague answers, such as kind of, more or less, I'm afraid, probably, as far as I can tell, etc. But if they use too many hedges, journalists would also feel dissatisfied. Fourth, Spokesperson should know how to make the atmosphere alive with appropriate humor ${ }^{[7]}$. For example, Obama used I've got a list of who's been naughty and nice to call on at the beginning of the press conference to make a good atmosphere.

\section{Research Methods and Data Collection}

Since the aim of present research is to investigate the frequency and the pragmatic functions of hedges strategically used in press conference language, it ranges from a macro-investigation by Micro-Concord Tool to a micro-discourse analytic examination. The first part concerned the identification and frequency of hedges used by American Whitehouse spokesperson; the second part examined the functional uses of hedges in press conference language ${ }^{[8]}$.

There are five texts selected from the transcripts of Whitehouse spokesperson remarks in Whitehouse press conference as a corpora ${ }^{[9]}$. The total number of words in these texts selected is about 31,984. Due to the large number of words, the software Micro-Concord is employed to help collect frequencies and percentages of hedges. Next, in light of definition and classification of hedge, the contexts with hedges are identified and analyzed for its pragmatic functions.

\section{Statistical Analysis and Results Discussion}

As the first step in the analysis, the tool Micro-concord is used to calculate the frequency and percentages of hedges according to the above-mentioned classification of hedges. Results are given in Table 1.

Table 1 The frequency and percentage of hedges in the corpus

\begin{tabular}{|c|c|c|c|}
\hline Samples & Total Number of Words & Total Number of Hedges & Percentage \\
\hline Sample 1 & 11287 & 451 & $4.01 \%$ \\
\hline Sample 2 & 3205 & 158 & $4.92 \%$ \\
\hline Sample 3 & 2109 & 73 & $3.46 \%$ \\
\hline Sample 4 & 8736 & 356 & $4.08 \%$ \\
\hline Sample 5 & 6647 & 284 & $4.27 \%$ \\
\hline Total & 31984 & 1322 & $4.13 \%$ \\
\hline
\end{tabular}


From Table 1, it can be seen that the number of words in selected texts is 31,984 , of which the number of hedges is 1322 . In sample 1 , there are 11287 words in the text, of which the number of hedges is highest. While in sample 3, hedges only account for $3.46 \%$.

The hedges in the spokesperson remarks of press conference can be classified into two categories based on Prince et al.'s classification, as can be seen in the following table.

Table 2 The identification of hedges in the corpus

\begin{tabular}{|l|c|c|}
\hline $\begin{array}{l}\text { Classification of } \\
\text { Hedges }\end{array}$ & Frequency & Percentage \\
\hline Approximators & 687 & $52 \%$ \\
\hline Shields & 635 & $48 \%$ \\
\hline Total & 1322 & $100 \%$ \\
\hline
\end{tabular}

From the above table, it is clear that the number of approximators is more than that of shields, which accounts for $52 \%$. Shields are less frequently used by spokesperson in the press conference, which is only $48 \%$.

\section{Pragmatic Analysis of Hedges}

From the frequency of hedges showed above in the tables, it can be seen that hedges are frequently used by Whitehouse spokesperson in press conference. Next, the 31984-word texts in the press conference language corpus are examined carefully to identify the pragmatic functions of hedges in each case, and then list those in which hedges are used based on the Prince et al.'s classification criteria.

The first part attempts to make an analysis of hedges in the perspective of Cooperative Principle. According to Cooperative Principle, the speakers in the communication should observe the following maxims: the maxim of quantity, the maxim of quality, the maxim of relation and the maxim of manner. The speakers should try his best to make his contribution as informative as is required, make his contribution one that is true, be relevant and be perspicuous.

However, it can be seen that hedges are used frequently in press conference language. It seems that the spokesperson violates the cooperative principle on purpose to make a good combination of literal meaning and the actual meaning. Based on the politeness, face-saving strategies can explain why spokesperson usually flout the maxims ${ }^{[10]}$. Brown and Levinson's face (1975) theory pointed out that face can be subdivided into negative face and positive face. The participants in the conversation have the right not to be interfered and commend his self-image. To make an effective communication, the participants should pass appropriate information, and in the process of which both sides should also keep face. To keep both sides' faces, positive face strategy and negative face strategy are employed. Some typical examples could be analyzed into details in the following categories. Positive face strategy could be seen in presupposition.

Q: I was curious if the President regrets or wants to clarify his characterization

Mr. Spicer: I've addressed this multiple times in the past. He has a healthy respect for the press. But I think that it's a two-way street, as I've also said before, and I think that the President understands that..... (cerpt from sample 1)

There are more cases in the application of negative face strategy in the press conference language.

Indirect devices. If-clauses are frequently used in order to save the negative face of the journalist and audience.

If you come here or want to express views that seek to do our country or our people harm, he is going to fight it aggressively, ...... (Excerpt from sample 1)

Minimizing the imposition I think. I think that the President, in terms of his desire to combat radical Islamic terrorism, he understands that people who want to express a peaceful position have every right in our Constitution. (Excerpt from sample 1) 
Devices of hedge. In Brown and Levinson's (1987) view, hedges facilitate the mitigation of threat on audiences' negative face, by using words like maybe, may, sort of, assume, etc.

And I think part of this is to make sure that the American people are reminded how prevalent some of these attacks and how much time and attention they have or have not gotten...... (Excerpt from sample 10)

Otherwise, as the spokesperson of the government, exaggerating facts or any kind of avoiding the question is inappropriate.

From above analysis, while spokesperson tries to observe cooperative principle, face-saving strategies are also frequently employed to make a good atmosphere and an effective communication in the press conference.

\section{Conclusion}

Based on Grice's cooperative principle and Brown \& Levinson's face theory, ten transcripts are randomly chosen and analyzed for the use of hedges in Whitehouse press conference language. The present study yielded the following important findings.

First, hedges are frequently used in press conference and can be subdivided into approximators and shields. Second, with cooperative principle and face theory, positive face strategy and negative face strategy are frequently used by Whitehouse spokesperson in press conference, especially indirect devices, devices of minimizing the imposition and devices of hedges in negative face strategy. As for the reason, it is thought that press conference language should be formal and frank to make a good image for the government and establish good relationship between the government and the public.

\section{References}

[1] Y. Wang: A Comparative Study of Pragmatic Vagueness in Chinese and English Diplomatic Language. (MS. Guizhou Normal university, China 2016), p.49.

[2] Prince, E.F., Bosk, C. \&Frader, J, On Hedging in Physician-physician Discourse, in: di Pietro, R.J. (Ed.), Linguistics and the Professions, Ablex Publishing Corporation, Norwood, New Jersey, 1982, pp. 83-97.

[3] Sinclair J. Corpus, Concordance, Collocation, Oxford University Press, Oxford, 2012.

[4] L.J. Chen: Cultural Context and Political Discourse. (Ph.D., Shanghai International Studies University, China 2007), p.142.

[5] Y. Y. Zheng: Analysis on Discourse Function of Government Spokesperson. (MS. Bohai University, China 2012) p.30.

[6] G. T. Wang: The Analysis of News Spokesman Language. (MS. Jilin University, China 2014), p.5.

[7] X. Y. Shen: Study on Government Spokesperson Discourse. (MS. East China Normal University, China 2012) p.55.

[8] X. M. Wang. Government Spokesman, Xinhua Press, Beijing, 2012.

[9] Information on http://www.whitehouse.gov/the_press_office/

[10] X. R. Zhang: Study of Face-saving Strategies on the U.S. Whitehouse Spokespersons. (MS., Jilin University, China 2014), p.22. 